\title{
ELISA-Based Measurement of Antibody Responses and PCR-Based Detection Profiles Can Distinguish between Active Infection and Early Clearance of Borrelia burgdorferi
}

\author{
John J. Lazarus, Akisha L. McCarter, Kari Neifer-Sadhwani, and R. Mark Wooten \\ Department of Medical Microbiology and Immunology, University of Toledo College of Medicine, Toledo, OH 43614, USA \\ Correspondence should be addressed to R. Mark Wooten, r.mark.wooten@utoledo.edu \\ Received 8 July 2011; Accepted 19 August 2011 \\ Academic Editor: Joanna Zajkowska
}

Copyright (c) 2012 John J. Lazarus et al. This is an open access article distributed under the Creative Commons Attribution License, which permits unrestricted use, distribution, and reproduction in any medium, provided the original work is properly cited.

\begin{abstract}
Borrelia burgdorferi is a spirochetal bacterium that causes Lyme disease. These studies address whether current research methods using either ELISA to detect seroconversion to B. burgdorferi antigens or PCR quantification of bacterial DNA within tissues can accurately distinguish between a productive infection versus a $B$. burgdorferi exposure that is rapidly cleared by the innate responses. Mice receiving even minimal doses of live B. burgdorferi produced significantly more B. burgdorferi-specific IgM and IgG than groups receiving large inocula of heat-killed bacteria. Additionally, sera from mice injected with varied doses of killed $B$. burgdorferi recognized unique borrelial antigens compared to mice infected with live B. burgdorferi. Intradermal injection of killed B. burgdorferi resulted in rapid DNA clearance from skin, whereas DNA was consistently detected in skin inoculated with viable B. burgdorferi. These data indicate that both ELISA-based serological analyses and PCR-based methods of assessing B. burgdorferi infection clearly distinguish between an established infection with live bacteria and exposure to large numbers of bacteria that are promptly cleared by the innate responses.
\end{abstract}

\section{Introduction}

Borrelia burgdorferi $(\mathrm{Bb})$ is a spirochetal bacterium that causes Lyme disease [1]. Introducing this pathogen into the skin of susceptible hosts, either via the bite of an infected tick or by injection of culture-grown bacteria, leads to their subsequent dissemination to several tissues, including heart, joint, and neural tissues [2]. These spirochetes are notable in their ability to persist for months to years within host tissues, with intermittent reemergence promoting the acute localized inflammatory lesions that characterize Lyme disease. While these persistent bacteria elicit strong innate and adaptive immune responses, their fastidious growth requirements have hindered in vitro analyses to determine which elements of host immunity are most important for controlling these infections [3-7].

Most studies to assess immune responses against $B$. burgdorferi are performed using a well-described murine model of Lyme disease. Mice are a natural reservoir for B. burgdorferi, and persistent bacteria within certain inbred strains are associated with similar tissues and produce inflammatory pathology consistent with that exhibited in human patients, though the severity of disease can vary widely between different inbred mouse strains [8-10]. Infection studies using inbred strains have allowed identification of specific immune mediators that affect host clearance, such as Toll-like receptor 2 (TLR2) [11, 12], MyD88 [13, 14], CD14 $[15,16]$, IL-10 $[17,18]$, the chemokine KC $[19]$, and the production of antibodies against critical $B$. burgdorferi antigens [20-24].

Studies elucidating the basis of B. burgdorferi clearance have relied heavily on two parameters, namely, seroconversion to bacterial antigens and detection of bacterial DNA in host tissues. Production of high antibody titers against certain B. burgdorferi antigens, which have been further characterized using western blot analyses, can protect animals from both tick-mediated and syringe challenge with $B$. burgdorferi $[9,22,25]$. The specific effects of antibodies and other immune mediators on B. burgdorferi clearance have traditionally been measured qualitatively by culturing murine 
tissues in sterile BSK medium and determining whether resident spirochetes can grow from these cultures [26]. More recently, real-time PCR techniques have been developed that can accurately quantify even minute $B$. burgdorferi levels in murine target tissues $[17,27,28]$, and similar methods have been used to compare the upregulation of targeted murine and bacterial gene products within infected tissues $[18,29,30]$. The refinement of these techniques have greatly improved the usefulness of the murine model of Lyme disease, particularly in identifying immune mediators that are effective in controlling these unique pathogens.

While both ELISA techniques, to measure antibody levels, and PCR analyses, to determine B. burgdorferi levels, are widely used to assess the development of Lyme disease in infected animals, questions have been raised regarding how accurately these techniques assess the infection status. B. burgdorferi are known to be highly immunogenic, largely due to the wide range of lipoproteins that are produced in response to different environmental cues $[6,31,32]$. These lipoproteins all possess a triacyl modification on their amino terminus [33] that not only activates many different host immune cells through interaction with TLR2 [11, 3436] but also provides potent adjuvant activity that significantly enhances antibody responses to these lipoproteins $[37,38]$. This raises the possibility that mice receiving a significant inoculum may produce substantial B. burgdorferispecific antibodies that do not truly reflect a response to an active infection, but alternatively reflect an antibody response to an initial inoculum that was quickly cleared; in these cases, differences between active and subclinical infection would only be apparent by subsequent western blot analyses. A second issue is that B. burgdorferi can persist in many different tissues, but the precise extracellular or intracellular microenvironment in which they persist, as well as the immunoprivileged status of that niche, is still being defined [39-42]. It is plausible that bacterial products from killed bacteria, such as DNA, might escape timely or complete clearance from those tissues, and, thus, subsequent assessment could falsely indicate that viable $B$. burgdorferi were persisting in those tissues. To address these issues, we have injected mice with various doses of live and heat-killed bacteria to determine whether significant and characteristic differences in both antibody production, as assessed by ELISA analyses, and detection of B. burgdorferi DNA, by PCR, can accurately reflect whether the mice were actively infected or were only exposed to a threshold level of bacterial antigens.

\section{Materials and Methods}

2.1. Infection of Mice with Borrelia burgdorferi. C57BL/6NCr (B6) mice were obtained from the National Cancer Institute: Frederick Animal Production Program (Frederick, MD). Mice were housed in the Department of Lab Animal Resources at the University of Toledo Health Sciences Campus according to the National Institutes of Health guidelines for the care and use of laboratory animals. All protocols were reviewed and approved by the Institutional Animal Care and Usage Committee.
The clonal N40 isolate [43] of B. burgdorferi was generously provided by Steve Barthold (University of California, Davis) as a passage two culture after isolation from the urinary bladder of a Rag- $1^{-/-}$mouse. For all infections, a passage 4 culture was grown in BSK-II medium supplemented with $6 \%$ rabbit serum (Sigma Chemical, St. Louis, Mo, USA) for $3-5$ days at $33^{\circ} \mathrm{C}$ and directly enumerated using a PetroffHauser's chamber and dark field microscopy. B6 naïve mice were infected with the indicated numbers of viable or heatkilled B. burgdorferi in a $20 \mu \mathrm{L}$ volume by intradermal injection into a shaven back. These bacteria remain intact after heat killing $\left(55^{\circ} \mathrm{C}\right.$ for 1 hour $)$ based on visual inspection and counting by dark field microscopy but are subsequently unable to grow in BSK medium (data not shown).

2.2. Immunoglobulin (Ig) Quantification. Serum was obtained at the indicated times by either retroorbital bleeding or exsanguination, and Ig content was assessed using previously described ELISA techniques [17]. Briefly, microtiter plates were coated with either sonicated B. burgdorferi or goat antibodies to mouse IgG, IgM, and IgA (Southern Biotech, Birmingham, Ala, USA). Multiple serum dilutions were added to plates for $90 \mathrm{~min}$ at $37^{\circ} \mathrm{C}$, and bound murine Ig was detected by addition of isotype-specific HRP-conjugated antibodies (Southern Biotech). Ig content was quantified by comparison to standard curves constructed by using purified Ig of the appropriate isotype (Southern Biotech).

2.3. Western Blot Analysis. One hundred twenty $\mu \mathrm{g}$ of sonicated cN40 isolate were electrophoresed in a $4-12 \%$ Bis-Tris gel (Invitrogen) containing a single large well, transferred to Immobilon-P membrane (Millipore, Bedford, Mass, USA), and immunoblotted using a Surf Blot apparatus (Idea Scientific Company, Minneapolis, Minn, USA). Immune sera used to blot the membrane were obtained from B6 mice at day 28 after inoculation with viable or heat-killed B. burgdorferi. Antibody-antigen complexes were detected by addition of HRP-conjugated antibodies specific for total murine Ig (Southern Biotech) and visualized by chemiluminescence. Multiple film exposure times were acquired for each blot to ensure that all protein bands were recorded irrespective of concentration variances between samples.

2.4. DNA Preparation. Murine skin tissues encompassing $(6 \mathrm{~mm}$ diameter) the $\mathrm{Bb}$ injection site were harvested from experimental animals sacrificed at the indicated times after injection, and DNA was prepared from individual tissues as previously described [10]. Briefly, tissue specimens were incubated in $0.1 \%$ collagenase A (Roche Diagnostics, Indianapolis, Ind, USA) at $37^{\circ} \mathrm{C}$ overnight, followed by the addition of an equal volume of $0.2 \mathrm{mg} / \mathrm{mL}$ proteinase $\mathrm{K}$ (Invitrogen, Carlsbad, Calif, USA) and incubation overnight at $55^{\circ} \mathrm{C}$. DNA was recovered by multiple phenol-chloroform extractions and ethanol precipitation and includes digestion of contaminating RNA in $1 \mathrm{mg} / \mathrm{mL}$ DNase-free RNase (Sigma), with the final sample resuspended in $500 \mu \mathrm{L}$ of TE buffer. The DNA content was quantified by absorbance at $260 \mathrm{~nm}$, and working samples were diluted to $50 \mu \mathrm{g} / \mathrm{mL}$ for quantitative real-time PCR analyses. 
2.5. Quantification of B. burgdorferi in Mouse Tissues. The number of spirochetes resident in the different murine target tissues were determined via PCR analyses using a LightCycler (Roche Diagnostics) rapid fluorescence temperature cycler based on our previously described protocols $[17,28]$. Briefly, amplification was performed on $100 \mathrm{ng}$ of template DNA in a $10 \mu \mathrm{L}$ final volume containing $50 \mathrm{mM}$ Tris $(\mathrm{pH} 8.3)$, $3 \mathrm{mM} \mathrm{MgCl}_{2}, 4.5 \mu \mathrm{g}$ of bovine serum albumin, $200 \mu \mathrm{M}$ of each deoxynucleoside triphosphate, a $1: 10,000$ dilution of SYBR Green I (Molecular Probes, Eugene, Ore, USA), $1 \mu \mathrm{M}$ of each primer (Integrated DNA Technologies, Coralville, Iowa, USA), and 0.5 U of Platinum Taq DNA Polymerase (Invitrogen). Copy numbers for the mouse nidogen and $B$. burgdorferi recA genes present in each sample were calculated by extrapolation to standard curves using LightCycler software (Roche Diagnostics). The reported data represents recA values that were corrected by normalization based on the nidogen (nid) gene copy number. The oligonucleotide primers used to detect mouse nidogen were nido.F (5'-CCA GCC ACA GAA TAC CAT CC- $\left.3^{\prime}\right)$ and nido.R (5' GGA CAT ACT CTG CTG CCA TC- $3^{\prime}$ ). The oligonucleotide primers used to detect $B$. burgdorferi recA were nTM17.F (5'-GTC GAT CTA TTG TAT TAG ATG AGG CTC TCG-3') and nTM17.R ( $5^{\prime}$-GCC AAA GTT CTG CAA CAT TAA CAC CTA AAG-3').

2.6. Statistical Analyses. The statistical significance of the quantitative differences between the different sample groups was determined by application of Student's two-tailed $t$-test; $P$ values that were $\leq 0.05$ were considered significant.

\section{Results}

3.1. Quantification of Bb-Specific Ig Levels in Serum. We initially wanted to determine whether distinct quantitative differences are detectable in antibody levels produced during an active $\mathrm{Bb}$ infection versus bacterial exposures that are quickly resolved. To address this, groups of B6 mice were injected with different doses of live or heat-killed bacteria, and the Bb-specific Ig content of individual sera collected either 2 or 4 weeks after infection was compared by ELISA analysis. Sera from control mice that were injected only with BSK II medium contained no Bb-specific IgG and minimal levels of Bb-specific IgM (Figure 1), which reflects the presence of natural Bb-specific IgM in naïve mice, as previously reported $[44,45]$. Mice injected with live bacteria showed higher Bb-specific IgM levels at 2 weeks (Figure 1(a)) than at 4 weeks (data not shown), and while low levels of Bb-specific IgG were seen at 2 weeks after infection (data not shown), the levels were much higher at 4 weeks postinfection (Figures 1(a) and 1(b)). Injecting a single dose of heat-killed $\mathrm{Bb}$ into B6 mice, with or without CFA, did not elicit significantly enhanced IgM levels compared to mice receiving BSK II medium alone (Figure 1(a)), even at a dose of $5 \times 10^{7}$ killed $\mathrm{Bb}$. However, injection of as few as 250 live bacteria increased the Bb-specific IgM levels by over 200fold compared to mice receiving the highest dose of killed bacteria $\left(P \leq 1.6 \times 10^{-5}\right)$ by 2 weeks post-infection. A
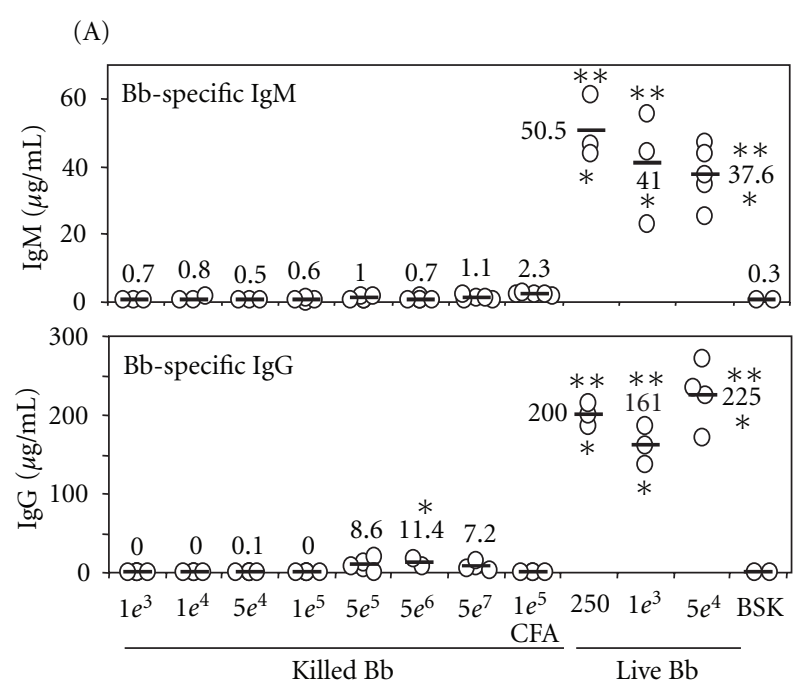

(B)

(a)
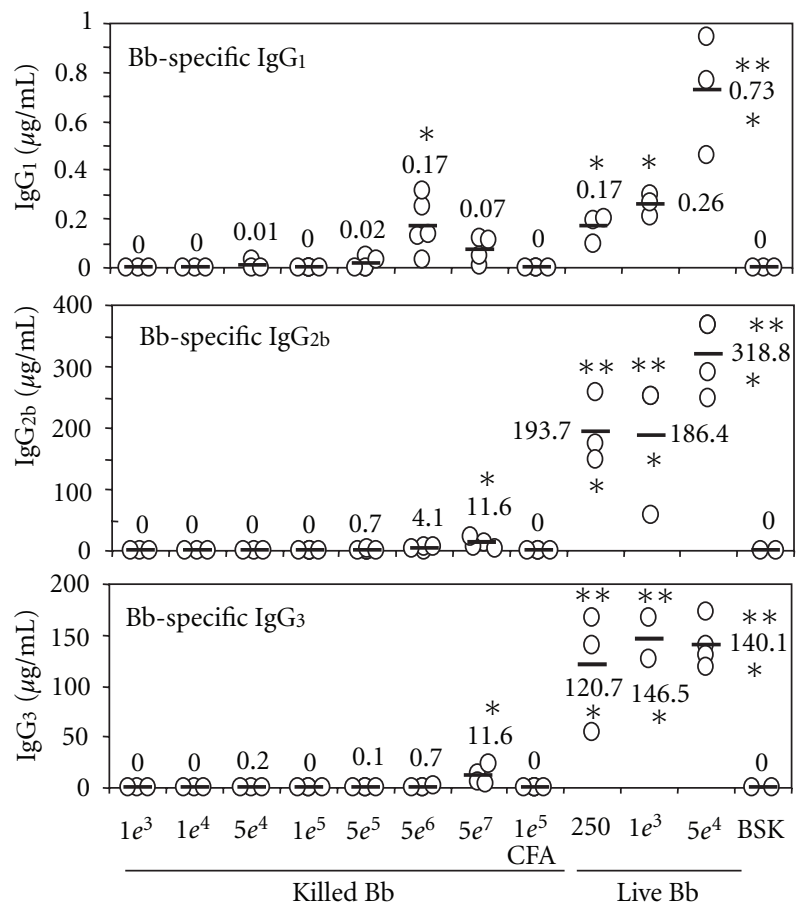

(b)

Figure 1: Comparison of Bb-specific antibody levels produced during active infection versus exposure to high numbers of killed bacteria. (a) Groups of B6 mice were injected with a single dose of live or heat-killed $\mathrm{Bb}$, and serum was collected at either 2 or 4 weeks after infection; in some cases the killed $\mathrm{Bb}$ inoculum included an equal volume of complete Freund's adjuvant (CFA). The doses

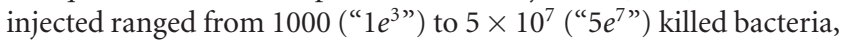
and 250 to $5 \times 10^{4}$ (“ $5 e^{4}$ ”) live $\mathrm{Bb}$. Individual sera were assessed for $\mathrm{Bb}$-specific IgM content at 2 weeks after infection and for IgG content at 4 weeks after infection by ELISA analyses. Each circle represents the serum value for an individual animal, and the number beside the bar indicates the average value for that group. * indicates values that are significantly different from control mice (Un); **indicates values that are significantly different from mice injected with killed bacteria. (b) The sera assessed for IgG content in (a) were also assessed for the levels of the indicated individual IgG isotypes using similar ELISA techniques. 
somewhat similar trend was seen in IgG levels at 4 weeks post-infection, where a dose of $5 \times 10^{6}$ killed $\mathrm{Bb}$ was required to significantly increase Bb-specific IgG levels compared to naïve mice $(P=0.011)$. Again, injection with as few as 250 live bacteria increased the Bb-specific IgG levels by over 20fold compared to mice receiving the highest dose of killed bacteria $\left(P \leq 2.3 \times 10^{-6}\right)$ by 4 weeks post-infection. These data indicate that significant quantitative differences in $\mathrm{Bb}$ specific antibodies are readily detected in sera from animals that sustain an active infection compared to those exposed to relatively high numbers of killed $\mathrm{Bb}$ that are quickly cleared.

To determine whether these differences in IgG production extended to all IgG isotypes, similar ELISA analyses were performed and developed using isotype-specific detection antibodies (Figure 1(b)). The production of $\operatorname{IgG}_{2 b}$ and $\mathrm{IgG}_{3}$ isotypes showed a similar trend as reported for Bb-specific $\mathrm{IgG}$, in that significant levels of Bb-specific antibodies were only observed at the very highest dose of killed bacteria, while administration of as few as 250 live $\mathrm{Bb}$ resulted in $\geq 10$ fold increase in Bb-specific antibodies $(P=0.001$ and 0.01 , resp.). In contrast, $\operatorname{IgG}_{1}$ production appeared much more responsive to killed bacteria, with significant increases in $\mathrm{Bb}$ specific $\operatorname{IgG}_{1}$ elicited in response to $5 \times 10^{6}$ killed bacteria, and these levels were similar to those produced in response to all live bacteria inocula, except for the highest dose. However, the overall quantities of $\operatorname{IgG}_{1}$ antibodies were $\geq 200$-fold less than the other isotypes assessed, and thus represent a minor component of the total IgG response.

3.2. Comparison of Bb Antigens Recognized by Antisera to Live and Killed $B b$. Bb can rapidly modulate a large number of surface-exposed and other lipoproteins during their natural infection cycle from arthropod to vertebrate host [31, 32, 46-48]. Therefore, it is likely that the antigens that are immunologically recognized during an active infection differ from those in a killed $\mathrm{Bb}$ exposure that is rapidly cleared, and could be used to further confirm the significant differences in antibody production observed in the ELISA analyses. To address this, sera were collected from mice injected with various doses of live and killed $\mathrm{Bb}$ at 4 weeks post-infection, and used for western blot analyses to compare the range of $\mathrm{Bb}$ antigens that are recognized by each serum (Figure 2). Mice injected only with BSK II medium (lanes 2-3) possessed no detectable $\mathrm{Bb}$-reactive antibodies, while a $\mathrm{mAb}$ specific for $\mathrm{Bb}$ OspA (lane 1) appeared to detect both the monomeric and dimeric forms of this lipoprotein. As expected based on the ELISA analyses (Figure 1), an approximately 20-fold higher concentration of serum from animals injected with killed bacteria was needed to effectively visualize $\mathrm{Bb}$ antigens compared to sera generated against live bacteria (Figure 2). Sera from mice that received either a single (lanes 7-9) or boosted dose (lane 13) of killed $\mathrm{Bb}$ demonstrated a protein recognition pattern that was distinct from mice receiving either a low (lanes 10-12) or high (lanes 14-16) dose of live $\mathrm{Bb}$. These studies indicate that significant quantitative and qualitative differences are apparent in the antibodies produced between mice that undergo an active infection with

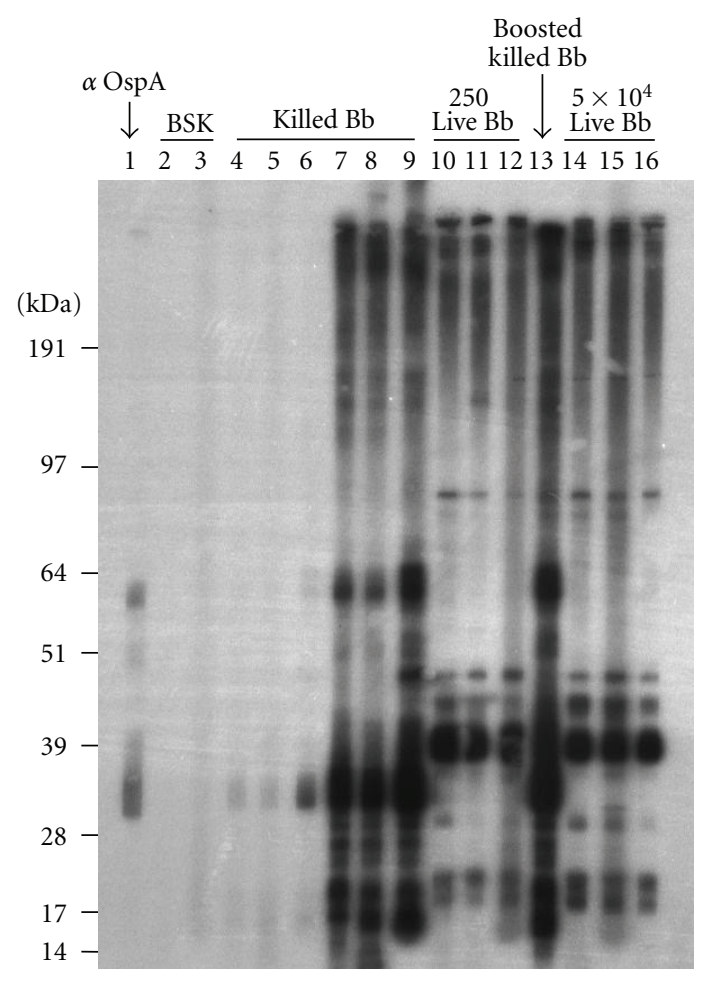

FIgURE 2: Antibodies produced against live and killed spirochetes recognize unique $\mathrm{Bb}$ antigens. Sera were collected from individual mice 4 weeks after injection with a single dose of either BSK II medium (lanes 2-3), $5 \times 10^{7}$ killed Bb (lanes 4-9), 250 live Bb (lanes 10-12), or $5 \times 10^{4}$ live $\mathrm{Bb}$ (lanes 14-16); one group initially received $10^{5}$ killed $\mathrm{Bb}+\mathrm{CFA}$, with a boost 3 weeks later with $10^{5}$ killed $\mathrm{Bb}+$ IFA, and sera collected 3 weeks later (lane 13). All sera were diluted either $1: 25$ (lanes 2-3 and 7-9) or 1:500 before using to immunoblot membranes containing electrophoresed $\mathrm{Bb}$. A mAb specific for Bb OspA, H5332 [49], was included as a marker for OspA reactivity (lane 1).

$\mathrm{Bb}$ and those which rapidly clear a relative large bacterial inoculum.

3.3. Persistence of Bb DNA in Skin Tissues. PCR-based assays are commonly used to quantify differences in Bb levels within host tissues for a number of model systems; however, it is not clear how long the DNA from killed bacteria might persist in those tissues and provide inaccurate estimation of the viable $\mathrm{Bb}$ numbers. To address this, parallel groups of mice were injected intradermally with either live or killed Bb, and skin tissues were harvested and assessed at different times after injection for the presence of bacterial DNA by real-time PCR using our described protocols $[17,28]$. Skin tissues harvested immediately after injection of equal numbers of live or killed $\mathrm{Bb}$ showed the presence of similar numbers of $\mathrm{Bb}$ genomes by PCR analyses (Figure 3), and, by $8 \mathrm{~h}$ after injection, these numbers have substantially decreased to similar low levels in animals receiving both live and killed bacteria. After $8 \mathrm{~h}$ after injection, almost no $\mathrm{Bb}$ genomes were detected in skin tissues of animals receiving killed bacteria (Figure 3), and more extensive studies showed that no $\mathrm{Bb}$ genomes were detected in skin, ear, ankle, or heart tissues of mice receiving killed 
bacteria at 2 and 4 weeks after injection (data not shown). Alternatively, mice receiving live bacteria showed a gradual increase in skin Bb levels after $8 \mathrm{~h}$ following infection, with the highest bacterial numbers detected at $96 \mathrm{~h}$ after infection (Figure 3), and reduced but consistent levels noted at 2 and 4 weeks after injection (data not shown). These findings suggest that killed $\mathrm{Bb}$ are rapidly cleared from skin tissues and that their genome content can no longer be detected by PCR within hours of being killed.

\section{Discussion}

The spirochetal pathogen B. burgdorferi $(\mathrm{Bb})$ is an obligate parasite that cycles efficiently between vertebrate and arthropod hosts and persists for extended periods within various host tissues. Antigenic variation has been described to play a putative role in immune evasion, but other mechanisms by which these bacteria evade clearance from immunocompetent hosts are not well defined. The fastidious growth requirements of these spirochetes make it difficult to design stringent in vitro analyses that accurately reflect host conditions. Therefore, infection studies using inbred mouse lines are the gold standard for addressing host- $\mathrm{Bb}$ interactions. Both ELISA and western blot analyses have been useful in measuring the critical antibody responses to $\mathrm{Bb}$ infection, including the identification of immunoreactive bacterial products that can confer protective immunity and in determining infection rates by seroconversion. Similarly, the recent development of quantitative real-time PCR techniques has allowed researchers to distinguish important differences in immune clearance between different murine model strains and, thus, identify mechanisms that are critical for clearance of these persistent bacteria. The sensitivity and specificity of these assays are well documented, but questions have arisen as to their abilities to differentiate between active infections versus those produced by residual and/or stimulatory bacterial products that persist subsequent to bacterial killing. Our study attempts to clarify the limitations of these techniques in assessing the murine infection model of Lyme disease.

B. burgdorferi is notable in that $\geq 8 \%$ of putative proteincoding genes contain a signal peptide "lipobox" region, suggesting that these gene products are recognized by lipid modification enzymes that produce triacylated lipoproteins $[6,7,33]$. These lipoproteins can be secreted across the cytoplasmic membrane to the outer membrane [50], where they are not only recognized by the adaptive immune responses but can also interact with TLR2 on a number of different immune cell types to induce inflammatory responses [11]. As a result of these interactions, Bb lipoproteins are highly immunogenic and possess endogenous adjuvant activities that make them attractive vaccine candidates $[38,51,52]$, such as the OspA-based LYMErix vaccine [53]. Infection with as few as 20 organisms can lead to the production of high levels of Bb-specific antibodies by 2 to 4 weeks after infection, which corresponds with a subsequent decrease of bacterial numbers in host tissues, suggesting the importance of these antibodies in controlling bacterial numbers $[22,54,55]$.

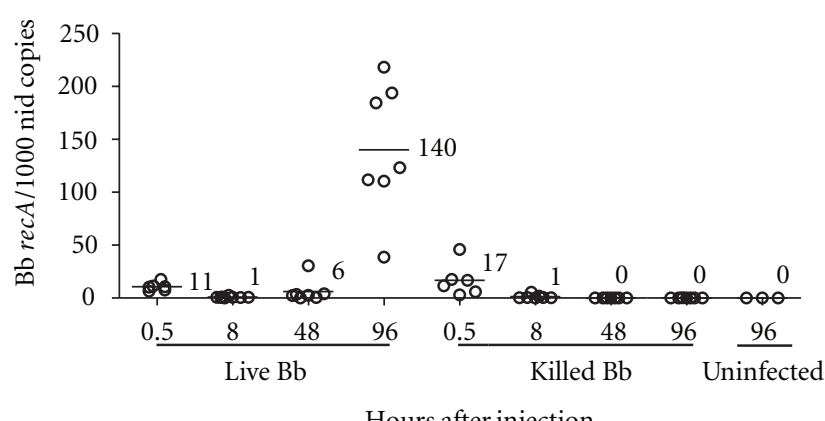

FIGURE 3: DNA from killed Bb is rapidly cleared from infection sites and is undetectable by PCR. Groups of mice were injected intradermally with $10^{4}$ of either live or heat-killed $\mathrm{Bb}$. Mice were sacrificed at the indicated times after injection, and a $6 \mathrm{~mm}$ skin sample encompassing the injection site was excised for DNA preparation. The relative $\mathrm{Bb}$ levels were assessed by real-time PCR using $\operatorname{rec} A$ primers and normalized relative to the murine nid content. Each circle represents $\mathrm{Bb}$ recA levels relative to 1000 nid copies for an individual animal, and the number beside the bar indicates the average value for that group. These data reflect the combined results of two separate experiments.

While increases in Bb-specific antibody levels are often used as an indicator of infection, it is possible that this correlation is misleading, since even a $\mathrm{Bb}$ inoculum that is rapidly cleared by the innate immune responses would result in the presentation of a substantial number of immunogenic lipoproteins to $\mathrm{T}$ and $\mathrm{B}$ cells, which could potentially elicit antibody levels that approach those produced by infected animals. However, we found that mice injected intradermally with a single dose of either live or heat-killed $\mathrm{Bb}$ produced sera with distinct differences. A dose of at least $5 \times 10^{6}$ killed bacteria was required to elicit detectable $\mathrm{Bb}$-specific antibodies, but even $5 \times 10^{7}$ killed bacteria elicited 20 - to 400-fold less Bb-specific antibody levels than any tested doses of live bacteria. These large differences were noted in all Ig isotypes tested except for $\operatorname{IgG}_{1}$ production. Overall, these data suggest that significant differences are apparent between the antibody levels produced in response to a productive $\mathrm{Bb}$ infection versus exposure to killed bacteria and that properly controlled ELISA analyses can reliably distinguish the two.

During their natural infection cycle, $\mathrm{Bb}$ must quickly adapt to a wide range of arthropod and vertebrate environments in order to survive. Many of these changes are associated with rapid expression changes involving multiple surface lipoproteins [56]. For example, OspA is highly expressed on the surface of $\mathrm{Bb}$ within the tick midgut or when cultured in BSK medium at ambient temperatures [47]. However, the process of tick feeding or increases in temperature cause the rapid downregulation of OspA and subsequent upregulation of numerous lipoproteins associated with mammalian infection, such as OspC [46, 57], the Erp family proteins [30], and different modifications of the $v l s E$-expressed lipoprotein [58]. Thus, Bb introduced into a murine host will differentially express a large number of different lipoproteins during the course of infection and should subsequently present a much broader range of antigens to host immune cells than $\mathrm{Bb}$ that are rapidly killed. 
Our studies determined that the $\mathrm{Bb}$ proteins recognized by sera from mice injected with killed $\mathrm{Bb}$ were distinct from the proteins recognized by sera from mice injected with live $\mathrm{Bb}$. Based on size and the OspA control, the response to killed $\mathrm{Bb}$ appeared largely directed against protein bands consistent with OspA monomers $(\sim 31 \mathrm{kDa})$ and dimers $(\sim 62 \mathrm{kDa})$, while the response to live $\mathrm{Bb}$ appeared directed to proteins with band sizes consistent with p39 $(\sim 39 \mathrm{kDa})$, flagellin $(\sim 41 \mathrm{kDa})$, and p93 ( $\sim 93 \mathrm{kDa})$; these different reactivities to proteins recognized on live $\mathrm{Bb}$ have been previously noted by different investigators [8, 46, 59-61]. Because these changes in antigen expression have been shown to correspond with active infection, our western blot data confirms that the significant differences in ELISA values can accurately distinguish between animals that experienced a progressive $\mathrm{Bb}$ infection versus an exposure to bacteria that could not adapt to escape host clearance.

Subsequent to inoculation in a murine host, $\mathrm{Bb}$ are known to disseminate from the skin and persist in a wide range of tissues (including the skin). While the precise environment that these bacteria prefer to persist within is not well defined, they are believed to largely exist extracellularly. $\mathrm{Bb}$ can associate with collagen bundles [62, 63], decorinassociated tissues [41, 64], or relatively avascular spaces throughout their host [65], all of which might provide some protection from immune recognition/clearance. Alternatively, $\mathrm{Bb}$ might be able to persist within some immune cells subsequent to phagocytosis, with both live and killed bacteria appearing to remain intact for extended periods of time [66]. These possibilities suggest that even $\mathrm{Bb}$ that are killed within host tissues might persist for extended times and, thus, could allow their cellular contents to be detected by assays designed to detect viable persistent bacteria, such as PCR of infected tissues. We addressed this by injecting mice with live and killed $\mathrm{Bb}$ and following the $\mathrm{Bb}$ content in the skin over time by PCR analysis. Levels of PCR-detectable bacteria declined to similar low levels by $8 \mathrm{~h}$ after injection in both groups, likely due to both the degradation of DNA content from killed $\mathrm{Bb}$, as well as the dissemination of live $\mathrm{Bb}$ away from the harvested skin injection site. However, the $\mathrm{Bb}$ DNA content in tissues receiving live bacteria increased to reach peak values by $96 \mathrm{~h}$ and subsequently remained low but significant. This pattern is consistent with previous reports of $\mathrm{Bb}$ persistence within skin tissues $[8,12]$. Our current studies suggest that killed $\mathrm{Bb}$ and their cellular content are efficiently cleared in skin tissues and should not be detectable by PCR methodologies within hours of being killed. In summary, both serological and PCR-based methods of assessing Bb infection clearly distinguish between an established infection with live bacteria and exposure to even large numbers of bacteria that are cleared early by the innate responses.

\section{Acknowledgments}

This work was supported by the Scientist Development Grant $0335148 \mathrm{~N}$ from the American Heart Association (R. M. Wooten) and, Public Health Service Grant R01-AI073452 from the National Institute of Allergy and Infectious Diseases
(R. M. Wooten). The authors wish to thank Robert Blumenthal and Isabel Novella for helpful discussions in writing this paper.

\section{References}

[1] W. Burgdorfer, A. G. Barbour, and S. F. Hayes, "Lyme disease-A tick-borne spirochetosis?" Science, vol. 216, no. 4552, pp. 1317-1319, 1982.

[2] A. C. Steere, J. Coburn, and L. Glickstein, "The emergence of Lyme disease," Journal of Clinical Investigation, vol. 113, no. 8, pp. 1093-1101, 2004.

[3] K. Von Lackum and B. Stevenson, "Carbohydrate utilization by the Lyme borreliosis spirochete, Borrelia burgdorferi," FEMS Microbiology Letters, vol. 243, no. 1, pp. 173-179, 2005.

[4] A. G. Barbour, "Isolation and cultivation of Lyme disease spirochetes," Yale Journal of Biology and Medicine, vol. 57, no. 4, pp. 521-525, 1984.

[5] R. J. Pollack, S. R. Telford, and A. Spielman, "Standardization of medium for culturing Lyme disease spirochetes," Journal of Clinical Microbiology, vol. 31, no. 5, pp. 1251-1255, 1993.

[6] C. M. Fraser, S. Casjens, W. M. Huang et al., "Genomic sequence of a Lyme disease spirochaete, Borrelia burgdorferi," Nature, vol. 390, no. 6660, pp. 580-586, 1997.

[7] S. Casjens, N. Palmer, R. Van Vugt et al., "A bacterial genome in flux: the twelve linear and nine circular extrachromosomal DNAs in an infectious isolate of the Lyme disease spirochete Borrelia burgdorferi," Molecular Microbiology, vol. 35, no. 3, pp. 490-516, 2000.

[8] S. W. Barthold, "Lyme borreliosis in the laboratory mouse," Journal of Spirochetal and Tick-borne Diseases, vol. 3, pp. 2244, 1996.

[9] S. W. Barthold, M. S. De Souza, J. L. Janotka, A. L. Smith, and D. H. Persing, "Chronic lyme borreliosis in the laboratory mouse," American Journal of Pathology, vol. 143, no. 3, pp. 959-972, 1993.

[10] Y. Ma, K. P. Seiler, E. J. Eichwald, J. H. Weis, C. Teuscher, and J. J. Weis, "Distinct characteristics of resistance to Borrelia burgdorferi induced arthritis in C57BL/6N mice," Infection and Immunity, vol. 66, no. 1, pp. 161-168, 1998.

[11] M. Hirschfeld, G. J. Kirschning, R. Schwandner et al., "Cutting edge: inflammatory signaling by Borrelia burgdorferi lipoproteins is mediated by toll-like receptor 2," Journal of Immunology, vol. 163, no. 5, pp. 2382-2386, 1999.

[12] R. M. Wooten, Y. Ma, R. A. Yoder et al., "Toll-like receptor 2 is required for innate, but not acquired, host defense to Borrelia burgdorferi," Journal of Immunology, vol. 168, no. 1, pp. 348355, 2002.

[13] D. D. Bolz, R. S. Sundsbak, Y. Ma et al., "MyD88 plays a unique role in host defense but not arthritis development in lyme disease," Journal of Immunology, vol. 173, no. 3, pp. 20032010, 2004.

[14] N. Liu, R. R. Montgomery, S. W. Barthold, and L. K. Bockenstedt, "Myeloid differentiation antigen 88 deficiency impairs pathogen clearance but does not alter inflammation in Borrelia burgdorferi-infected mice," Infection and Immunity, vol. 72, no. 6, pp. 3195-3203, 2004.

[15] R. M. Wooten, T. B. Morrison, J. H. Weis, S. D. Wright, R. Thieringer, and J. J. Weis, "The role of CD14 in signaling mediated by outer membrane lipoproteins of Borrelia burgdorferi," Journal of Immunology, vol. 160, no. 11, pp. 5485-5492, 1998.

[16] M. R. E. I. Benhnia, D. Wroblewski, M. N. Akhtar et al., "Signaling through CD14 attenuates the inflammatory 
response to Borrelia burgdorferi, the agent of lyme disease," Journal of Immunology, vol. 174, no. 3, pp. 1539-1548, 2005.

[17] J. P. Brown, J. F. Zachary, C. Teuscher, J. J. Weis, and R. M. Wooten, "Dual role of interleukin-10 in murine lyme disease: regulation of arthritis severity and host defense," Infection and Immunity, vol. 67, no. 10, pp. 5142-5150, 1999.

[18] J. J. Lazaras, M. J. Meadows, R. E. Lintner, and R. M. Wooten, "IL-10 deficiency promotes increased Borrelia burgdorferi clearance predominantly through enhanced innate immune responses," Journal of Immunology, vol. 177, no. 10, pp. 70767085, 2006.

[19] Q. Xu, S. V. Seemanapalli, K. E. Reif, C. R. Brown, and F. T. Liang, "Increasing the recruitment of neutrophils to the site of infection dramatically attenuates Borrelia burgdorferi infectivity," Journal of Immunology, vol. 178, no. 8, pp. 5109 5115, 2007.

[20] S. E. Connolly and J. L. Benach, "The versatile roles of antibodies in Borrelia infections," Nature Reviews Microbiology, vol. 3, no. 5, pp. 411-420, 2005.

[21] S. W. Barthold and L. K. Bockenstedt, "Passive immunizing activity of sera from mice infected with Borrelia burgdorferi," Infection and Immunity, vol. 61, no. 11, pp. 4696-4702, 1993.

[22] S. W. Barthold, M. DeSouza, and S. Feng, "Serum-mediated resolution of Lyme arthritis in mice," Laboratory Investigation, vol. 74, no. 1, pp. 57-67, 1996.

[23] A. M. De Silva, S. R. Telford, L. R. Brunet III, S. W. Barthold, and E. Fikrig, "Borrelia burgdorferi OspA is an arthropodspecific transmission-blocking Lyme disease vaccine," Journal of Experimental Medicine, vol. 183, no. 1, pp. 271-275, 1996.

[24] E. Fikrig, S. W. Barthold, F. S. Kantor, and R. A. Flavell, "Protection of mice against the Lyme disease agent by immunizing with recombinant OspA," Science, vol. 250, no. 4980, pp. 553-556, 1990.

[25] L. K. Bockenstedt, E. Fikrig, S. W. Barthold, F. S. Kantor, and R. A. Flavell, "Inability of truncated recombinant Osp A proteins to elicit protective immunity to Borrelia burgdorferi in mice," Journal of Immunology, vol. 151, no. 2, pp. 900-906, 1993.

[26] M. B. Lawrenz, R. M. Wooten, J. F. Zachary et al., "Effect of complement component C3 deficiency on experimental lyme borreliosis in mice," Infection and Immunity, vol. 71, no. 8, pp. 4432-4440, 2003.

[27] T. B. Morrison, J. J. Weis, and C. T. Wittwer, "Quantification of lowcopy transcripts by continuous SYBR green I monitoring during amplification,” BioTechniques, vol. 24, no. 6, pp. 954962, 1998.

[28] T. B. Morrison, Y. Ma, J. H. Weis, and J. J. Weis, "Rapid and sensitive quantification of Borrelia burgdorferi-infected mouse tissues by continuous fluorescent monitoring of PCR," Journal of Clinical Microbiology, vol. 37, no. 4, pp. 987-992, 1999.

[29] E. Hodzic, S. Feng, K. J. Freet, D. L. Borjesson, and S. W. Barthold, "Borrelia burgdorferi population kinetics and selected gene expression at the host-vector interface," Infection and Immunity, vol. 70, no. 7, pp. 3382-3388, 2002.

[30] J. C. Miller, K. Von Lackum, K. Babb, J. D. McAlister, and B. Stevenson, "Temporal analysis of Borrelia burgdorferi Erp protein expression throughout the mammal-tick infectious cycle," Infection and Immunity, vol. 71, no. 12, pp. 6943-6952, 2003.

[31] F. T. Liang, F. Kenneth Nelson, and E. Fikrig, "Molecular adaptation of Borrelia burgdorferi in the murine host," Journal of Experimental Medicine, vol. 196, no. 2, pp. 275-280, 2002.

[32] R. Tokarz, J. M. Anderton, L. I. Katona, and J. L. Benach, "Combined effects of blood and temperature shift on Borrelia burgdorferi gene expression as determined by whole genome
DNA array," Infection and Immunity, vol. 72, no. 9, pp. 54195432, 2004.

[33] J. C. Setubal, M. Reis, J. Matsunaga, and D. A. Haake, "Lipoprotein computational prediction in spirochaetal genomes," Microbiology, vol. 152, no. 1, pp. 113-121, 2006.

[34] A. O. Aliprantis, R. B. Yang, M. R. Mark et al., "Cell activation and apoptosis by bacterial lipoproteins through Toll- like receptor-2," Science, vol. 285, no. 5428, pp. 736-739, 1999.

[35] H. D. Brightbill, D. H. Libraty, S. R. Krutzik et al., "Host defense mechanisms triggered by microbial lipoproteins through toll-like receptors," Science, vol. 285, no. 5428, pp. 732-736, 1999.

[36] E. Lien, T. J. Sellati, A. Yoshimura et al., “Toll-like receptor 2 functions as a pattern recognition receptor for diverse bacterial products," Journal of Biological Chemistry, vol. 274, no. 47, pp. 33419-33425, 1999.

[37] J. J. Weis, Y. Ma, and L. F. Erdile, "Biological activities of native and recombinant Borrelia burgdorferi outer surface protein A: dependence on lipid modification," Infection and Immunity, vol. 62, no. 10, pp. 4632-4636, 1994.

[38] L. F. Erdile, M. A. Brandt, D. J. Warakomski et al., "Role of attached lipid in immunogenicity of Borrelia burgdorferi OspA," Infection and Immunity, vol. 61, no. 1, pp. 81-90, 1993.

[39] Y. Ma, A. Sturrock, and J. J. Weis, "Intracellular localization of Borrelia burgdorferi within human endothelial cells," Infection and Immunity, vol. 59, no. 2, pp. 671-678, 1991.

[40] J. A. Livengood and R. D. Gilmore, "Invasion of human neuronal and glial cells by an infectious strain of Borrelia burgdorferi," Microbes and Infection, vol. 8, no. 14-15, pp. 2832-2840, 2006.

[41] F. T. Liang, E. L. Brown, T. Wang, R. V. Iozzo, and E. Fikrig, "Protective niche for Borrelia burgdorferi to evade humoral immunity," American Journal of Pathology, vol. 165, no. 3, pp. 977-985, 2004.

[42] F. C. Cabello, H. P. Godfrey, and S. A. Newman, "Hidden in plain sight: Borrelia burgdorferi and the extracellular matrix," Trends in Microbiology, vol. 15, no. 8, pp. 350-354, 2007.

[43] S. W. Barthold, D. S. Beck, G. M. Hansen, G. A. Terwilliger, and K. D. Moody, "Lyme borreliosis in selected strains and ages of laboratory mice," Journal of Infectious Diseases, vol. 162, no. 1, pp. 133-138, 1990.

[44] A. A. Belperron and L. K. Bockenstedt, "Natural antibody affects survival of the spirochete Borrelia burgdorferi within feeding ticks," Infection and Immunity, vol. 69, no. 10, pp. 6456-6462, 2001.

[45] M. E. Woodman, A. E. Cooley, J. C. Miller et al., "Borrelia burgdorferi binding of host complement regulator factor $\mathrm{H}$ is not required for efficient mammalian infection," Infection and Immunity, vol. 75, no. 6, pp. 3131-3139, 2007.

[46] T. G. Schwan and J. Piesman, "Temporal changes in outer surface proteins $\mathrm{A}$ and $\mathrm{C}$ of the lyme disease- associated spirochete, Borrelia burgdorferi, during the chain of infection in ticks and mice," Journal of Clinical Microbiology, vol. 38, no. 1, pp. 382-388, 2000.

[47] T. G. Schwan, J. Piesman, W. T. Golde, M. C. Dolan, and P. A. Rosa, "Induction of an outer surface protein on Borrelia burgdorferi during tick feeding," Proceedings of the National Academy of Sciences of the United States of America, vol. 92, no. 7, pp. 2909-2913, 1995.

[48] B. Stevenson, T. G. Schwan, and P. A. Rosa, "Temperaturerelated differential expression of antigens in the Lyme disease spirochete, Borrelia burgdorferi," Infection and Immunity, vol. 63, no. 11, pp. 4535-4539, 1995. 
[49] A. G. Barbour, S. L. Tessier, and W. J. Todd, "Lyme disease spirochetes and Ixodid tick spirochetes share a common surface antigenic determinant defined by a monoclonal antibody," Infection and Immunity, vol. 41, no. 2, pp. 795-804, 1983.

[50] R. J. Schulze and W. R. Zückert, "Borrelia burgdorferi lipoproteins are secreted to the outer surface by default," Molecular Microbiology, vol. 59, no. 5, pp. 1473-1484, 2006.

[51] D. Keller, F. T. Koster, D. H. Marks, P. Hosbach, L. F. Erdile, and J. P. Mays, "Safety and immunogenicity of a recombinant outer surface protein A Lyme vaccine," Journal of the American Medical Association, vol. 271, no. 22, pp. 1764-1768, 1994.

[52] L. F. Erdile and G. Bruno, "OspA lipoprotein of Borrelia burgdorferi is a mucosal immunogen and adjuvant," Vaccine, vol. 15, no. 9, pp. 988-996, 1997.

[53] A. C. Steere, V. K. Sikand, F. Meurice et al., "Vaccination against lyme disease with recombinant Borrelia burgdorferi outer-surface lipoprotein A with adjuvant," New England Journal of Medicine, vol. 339, no. 4, pp. 209-215, 1998.

[54] S. W. Barthold, C. L. Sidman, and A. L. Smith, "Lyme borreliosis in genetically resistant and susceptible mice with severe combined immunodeficiency," American Journal of Tropical Medicine and Hygiene, vol. 47, no. 5, pp. 605-613, 1992.

[55] U. E. Schaible, R. Wallich, M. D. Kramer et al., "Protection against Borrelia burgdorferi infection in SCID mice is conferred by presensitized spleen cells and partially by B but not $\mathrm{T}$ cells alone," International Immunology, vol. 6, no. 5, pp. 671681, 1994.

[56] A. M. De Silva and E. Fikrig, "Arthropod- and host-specific gene expression by Borrelia burgdorferi," Journal of Clinical Investigation, vol. 99, no. 3, pp. 377-379, 1997.

[57] J. A. Carroll, C. F. Garon, and T. G. Schwan, "Effects of environmental $\mathrm{pH}$ on membrane proteins in Borrelia burgdorferi," Infection and Immunity, vol. 67, no. 7, pp. 31813187, 1999.

[58] J. R. Zhang and S. J. Norris, "Kinetics and in vivo induction of genetic variation of vlsE in Borrelia burgdorferi," Infection and Immunity, vol. 66, no. 8, pp. 3689-3697, 1998.

[59] W. J. Simpson, M. E. Schrumpf, and T. G. Schwan, "Reactivity of human Lyme borreliosis sera with a 39-kilodalton antigen specific to Borrelia burgdorferi," Journal of Clinical Microbiology, vol. 28, no. 6, pp. 1329-1337, 1990.

[60] J. L. Coleman and J. L. Benach, "Identification and characterization of an endoflagellar antigen of Borrelia burgdorferi," Journal of Clinical Investigation, vol. 84, no. 1, pp. 322-330, 1989.

[61] B. J. Luft, S. Mudri, W. Jiang et al., “The 93-kilodalton protein of Borrelia burgdorferi: an immunodominant protoplasmic cylinder antigen," Infection and Immunity, vol. 60, no. 10, pp. 4309-4321, 1992.

[62] A. R. Pachner, J. Basta, E. Delaney, and D. Hulinska, "Localization of Borrelia burgdorferi in murine lyme borreliosis by electron microscopy," American Journal of Tropical Medicine and Hygiene, vol. 52, no. 2, pp. 128-133, 1995.

[63] M. C. Zambrano, A. A. Beklemisheva, A. V. Bryksin, S. A. Newman, and F. C. Cabello, "Borrelia burgdorferi binds to, invades, and colonizes native type I collagen lattices," Infection and Immunity, vol. 72, no. 6, pp. 3138-3146, 2004.

[64] B. P. Guo, E. L. Brown, D. W. Dorward, L. C. Rosenberg, and M. Höök, "Decorin-binding adhesins from Borrelia burgdorferi," Molecular Microbiology, vol. 30, no. 4, pp. 711723, 1998.
[65] T. Haupl, G. Hahn, M. Rittig et al., "Persistence of Borrelia burgdorferi in ligamentous tissue from a patient with chronic Lyme borreliosis," Arthritis and Rheumatism, vol. 36, no. 11, pp. 1621-1626, 1993.

[66] R. R. Montgomery, M. H. Nathanson, and S. E. Malawista, "The fate of Borrelia burgdorferi, the agent for Lyme disease, in mouse macrophages: destruction, survival, recovery," Journal of Immunology, vol. 150, no. 3, pp. 909-915, 1993. 


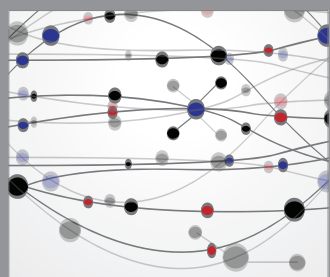

The Scientific World Journal
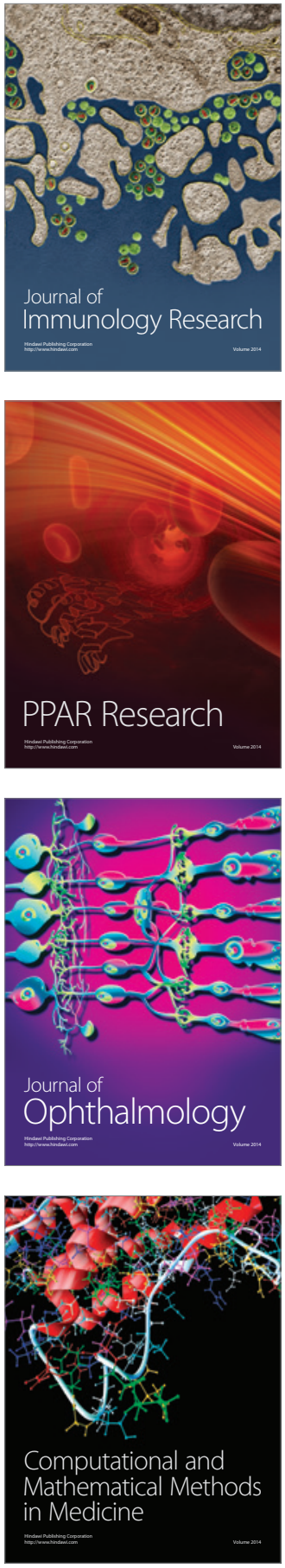

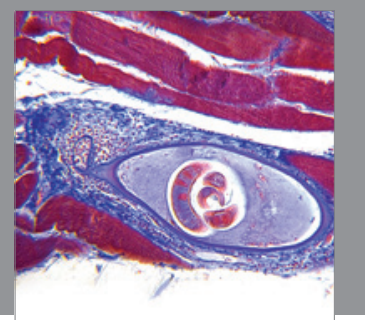

Gastroenterology

Research and Practice
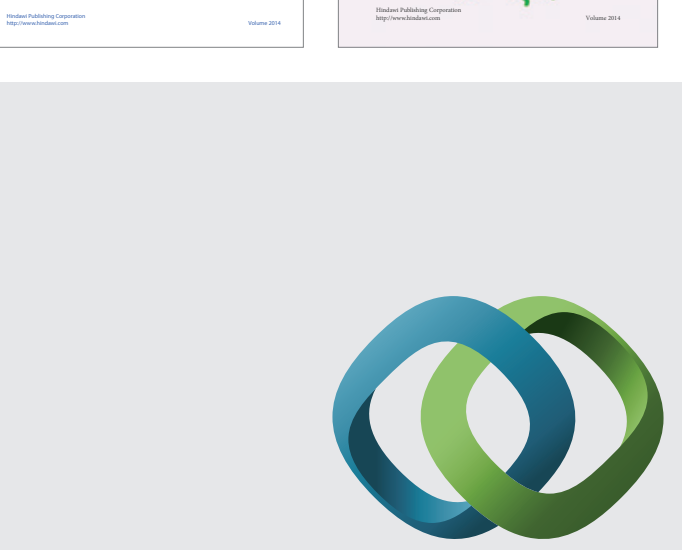

\section{Hindawi}

Submit your manuscripts at

http://www.hindawi.com
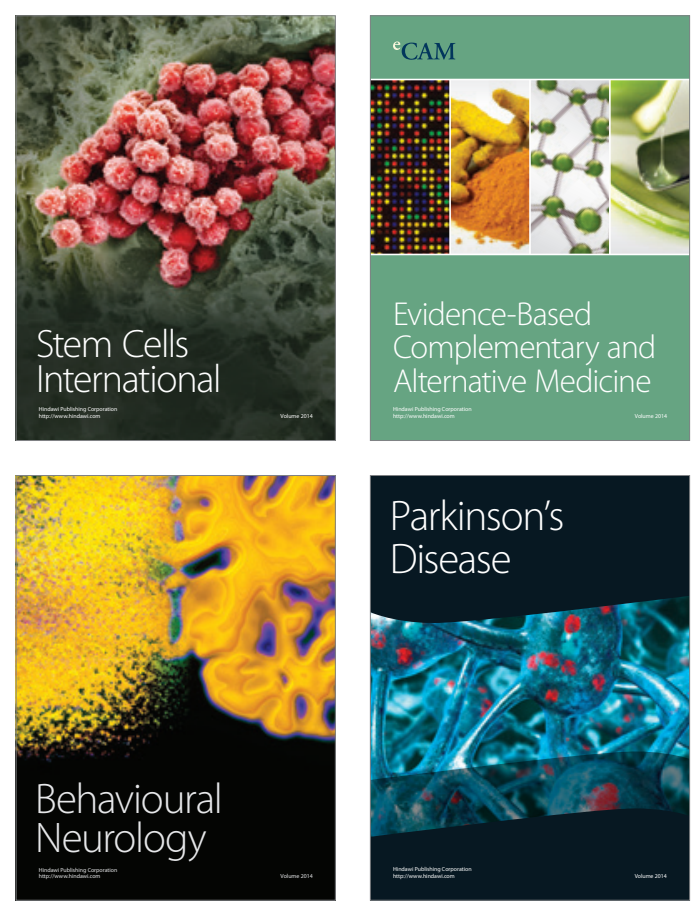

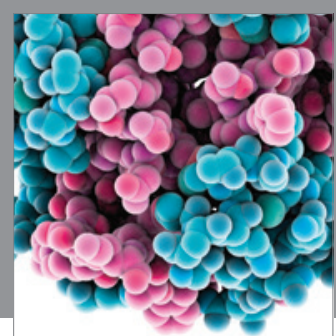

Journal of
Diabetes Research

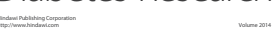

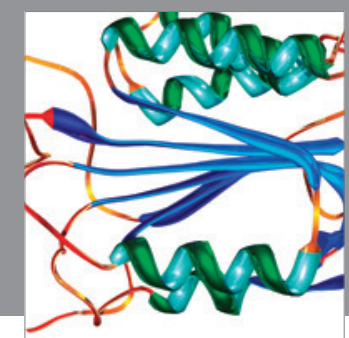

Disease Markers
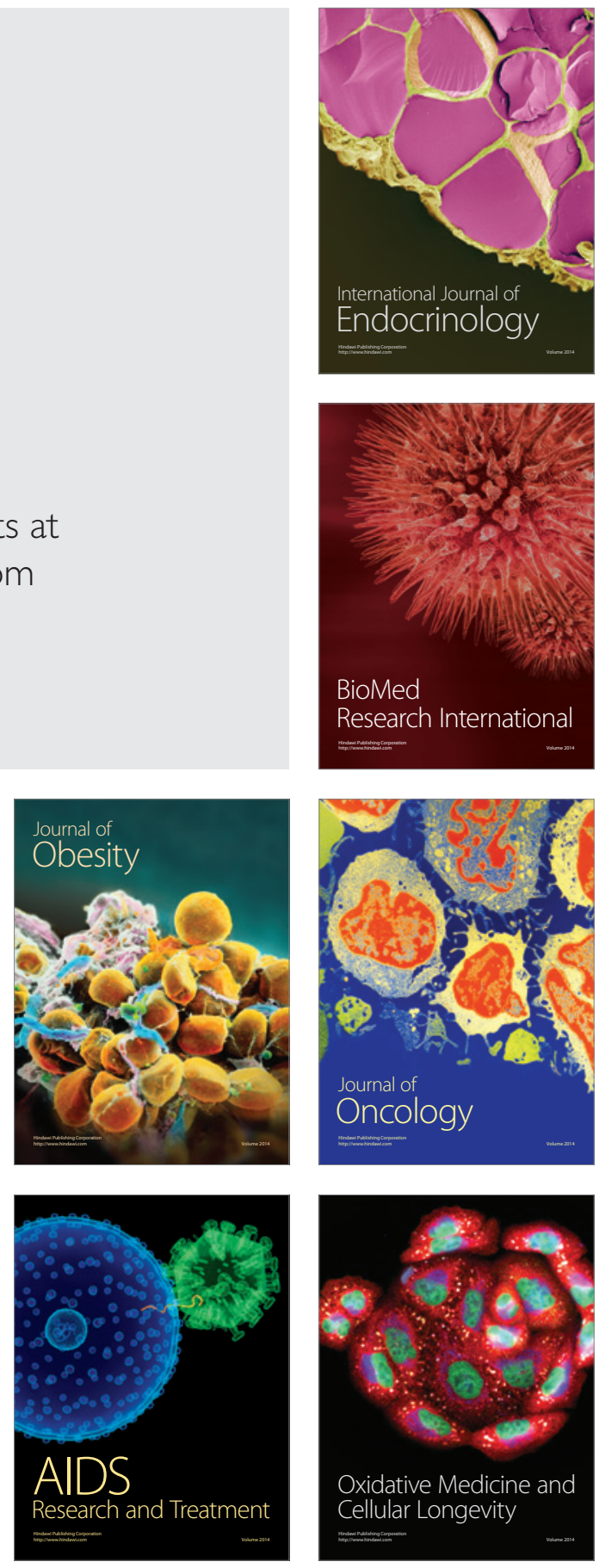